\title{
Ultrasound-guided pediatric vascular cannulation by inexperienced operators: outcomes in a training model
}

\author{
José Manuel López-Álvarez ${ }^{1,4}$. Olivia Pérez-Quevedo ${ }^{1}$. Joaquín Naya-Esteban ${ }^{2,4} \cdot$ Teresa Ramirez-Lorenzo $^{3}$. \\ Juan Carlos Falcón-González ${ }^{4}$. Dionisio Lorenzo Lorenzo-Villegas ${ }^{4}$
}

Received: 13 February 2021 / Accepted: 5 April 2021

(c) Società Italiana di Ultrasonologia in Medicina e Biologia (SIUMB) 2021

\begin{abstract}
Objective To present the results of an ultrasound vascular cannulation (UGVC) training program for inexperienced operators using a training model.

Method This was a descriptive observational study developed in the paediatric intensive care unit (PICU) of a third-level hospital. Operators received basic theoretical training in the USVC technique, followed by practical training with a model designed for USVC-inexperienced healthcare professionals.

Results The study included 25 healthcare professionals, who carried out a total of 300 ultrasound-guided cannulation procedures (12 per participant) at equidistant sites on the longitudinal axis/in-plane (LA/IP) and the transverse axis/out-of-plane (TA/OP). The mean depth of cannulated vessels was $0.90(0.34) \mathrm{cm}$ and their mean diameter was $0.41(0.1) \mathrm{cm}$. In $41.7 \%$ of cases, complete view of the needle $(\mathrm{CVN})$ was accomplished; in $49 \%$ of cases, repositioning of the needle/guidewire (RNG) was necessary for successful UGVC. The rate of successful UGVC in the training model was $79.7 \%$. The mean time required for the procedure was 74.70 (73.72) seconds. The time to successful cannulation was $58.72(56.87)$ seconds. The mean number of attempts needed until successful UGVC was 1.31 (0.72). Complications were: (a) $26.3 \%$ vessel perforation/wrong guidewire positioning (VP/WGP) and (b) $4.3 \%$ successful vessel puncture followed by failure to accomplish subsequent cannulation.

Conclusions Through the present theoretical-practical training program for inexperienced operators using a training model: (a) high success rates and short procedural times were attained; (b) complete view of needle and need for repositioning the needle/guidewire occurred in half of the procedures; and (c) complications occurred in a third of the procedures.
\end{abstract}

Keywords Simulation $\cdot$ Ultrasound $\cdot$ Vascular access $\cdot$ Paediatrics

José Manuel López-Álvarez

jmloal@hotmail.com; jmlopez@ufpcanarias.es

1 Pediatric Intensive Care Unit, Mother and Child University Hospital of the Canary Islands (Complejo Hospitalario Universitario Insular Materno-Infantil de Canarias), Las Palmas de Gran Canaria, Spain

2 Interventive Radiology Unit, Mother and Child University Hospital of the Canary Islands (Complejo Hospitalario Universitario Insular Materno-Infantil de Canarias), Las Palmas de Gran Canaria, Spain

3 Department of Biostatistics. Unit of de Support to Research, University of Las Palmas de Gran Canaria, Las Palmas de Gran Canaria, Spain

4 Department of Clinical Sciences, Fernando Pessoa Canarias University, Las Palmas de Gran Canaria, Spain

\section{Introduction}

Central vessel cannulation entails more difficulties in paediatric patients than in adult ones, and is not devoid of risks or complications. Obtaining vein access in paediatric patients may be a challenge for both medical and nursing staff [1-6]. Great advances were achieved using ultrasoundbased guidance [7-15]. However, such an approach requires a training process, which should ideally be completed in simulation models. Simulation models artificially reproduce conditions that may be encountered in the real world, thus allowing operators to train and acquire the necessary skills to perform a novel medical procedure [16-18]. Simulation models: (a) help improve the quality of patient assistance, especially with techniques that are not free of risks or complications; (b) reduce the stress associated to the use of a 
Fig. 1 Training model for ultrasound-guided vascular cannulation and puncture on the transverse axis/out-of-plane
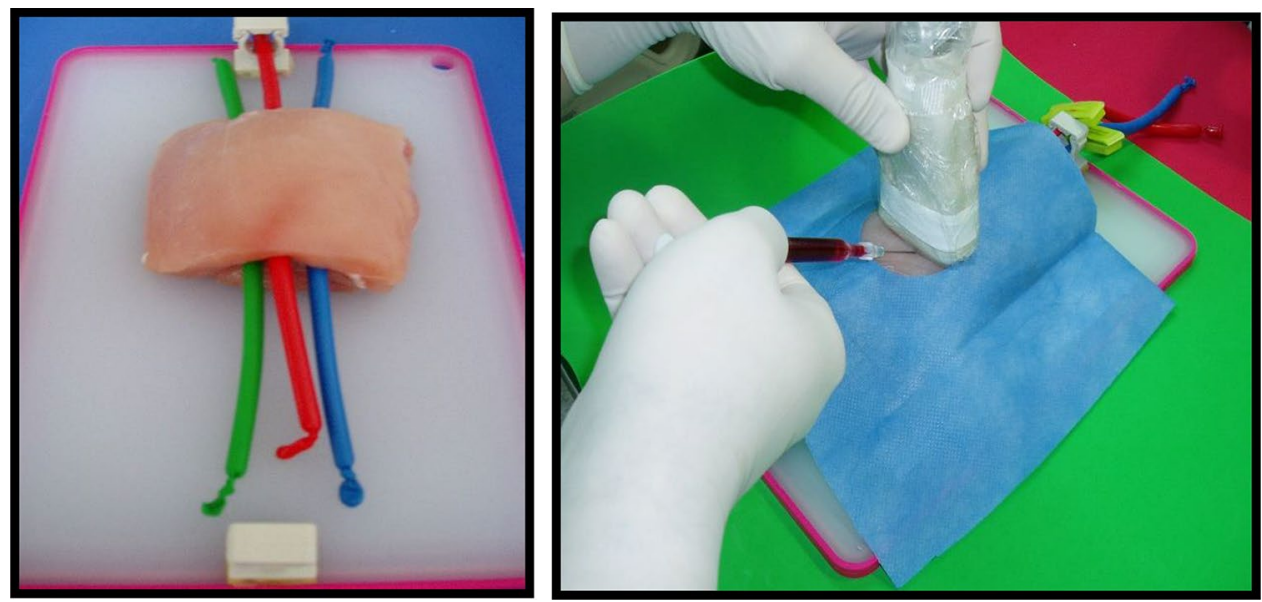

novel technique directly on patients; and (c) may be used as many times as the model is reproduced, helping solve problems that may emerge during in vivo application of the technique $[19,20]$. Ultrasound-guided vascular cannulation (UGVC) training programs facilitate the acquisition of basic knowledge on vascular ultrasound and its practical applications, and are generally carried out with simulation models $[16,17]$. The skills and abilities acquired with a model diminish the learning curve associated to the implantation of any technique [7-12]. The model used in this study [18] offered the possibility to adjust the technique to the vessel diameters and depths of paediatric patients. The results were used to evaluate the UGVC success rate, the manoeuvres that may potentially improve the procedure and the most frequent complications of the technique.

Many ultrasound-guided vascular cannulation simulators have been described [16-20]. The model presented here shows the following differential characteristics: (a) possibility to be adapted to different vascular sizes and depths, similarly to what occurs in a paediatric population, as this population shows a huge variability of weight, age and size, and, as a consequence, a high variability of vascular diameter and depth; (b) repeatability, reuse and easy transportation; (c) high fidelity as compared to patient puncture 'in vivo', given that it is a natural model; and d) low price [18]. The objectives of our study, which used this model, were to establish a UGVC training program for inexperienced operators and to present the results of a training program with a simulation model for paediatric UGVC.

\section{Method}

During the course of a 4-h UGCV training program ( $2 \mathrm{~h}$ theory plus $2 \mathrm{~h}$ practice), 25 operators without previous experience carried out a total of 300 punctures (12 per operator) at equidistant sites along the transverse axis out-of-plane

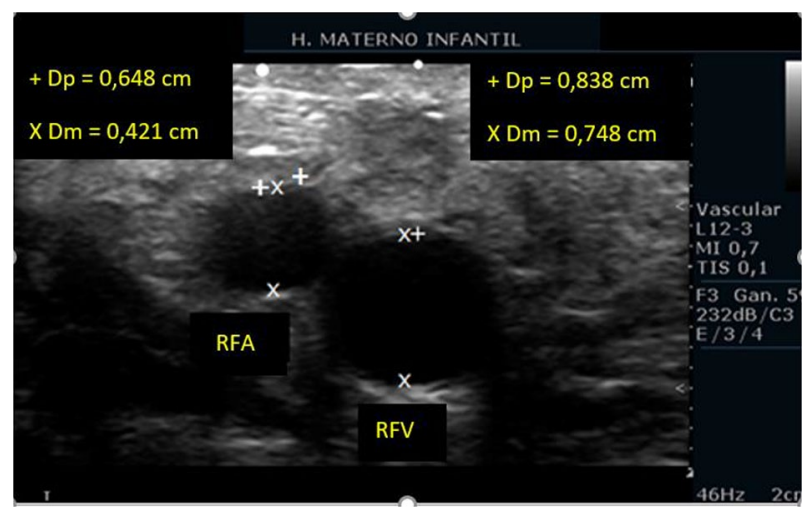

Fig. 2 Measurement of depth (Dp) and diameter (Dm) of the right femoral artery (RFA) and vein (RFV) in a 12-year-old patient

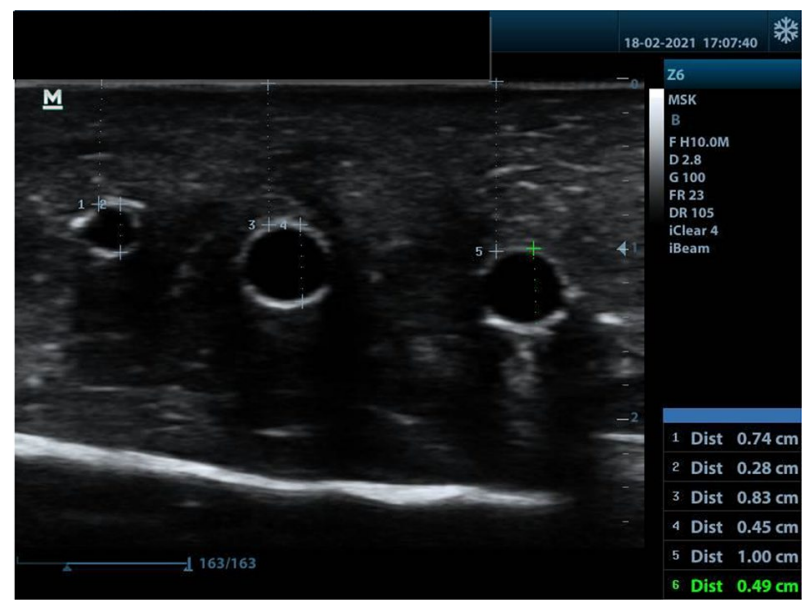

Fig. 3 Ultrasound image within the transverse axis of three vessels of different sizes and different depths, obtained by the simulation model

(TA/OP) or the longitudinal axis in-plane (LA/IP) using the simulation model developed by Pérez-Quevedo/López-Alvarez [18] (Fig. 1). The depth and diameter (Figs. 2, 3) of the 
vascular structures to be cannulated were established on the basis of previous determinations in paediatric patients [13, 14]. The ultrasound equipment was Sonosite NanoMaxx ${ }^{\circledR}$ Linear Probe (FUJIFILM Sonosite, Inc. 21919 30th Drive SE Bothell, Washington 98021-3904, USA) L25n frequency 13-6 MHz. The results of ultrasound-guided vessel punctures in the training model were used to evaluate the success rate of cannulation, the time needed for the procedure, the number of attempts needed to achieve successful cannulation, manoeuvres that might facilitate UGCV and potential complications during the application of the technique. Qualitative variables were expressed as frequencies and percentages. Numerical variables were expressed as mean, standard deviation, and median. Normality of the continual numerical variables was evaluated with the Kolmogorov-Smirnov test. The statistical analysis was conducted with the Statistical Package for the Social Sciences version 19 for Windows (SPSS Inc., Chicago, IL, USA).

\section{Results}

Twenty-five participants (56\% physicians and $44 \%$ nurses) without prior experience in UGCV carried out a total of 300 punctures (12 per participant) at equidistant sites along the TA/OP or LA/IP using the designed training model (Fig. 1). Table 1 shows the main characteristics of the UGVC model for inexperienced operators; notice that the mean depth of vessels to be cannulated was $0.90(0.34) \mathrm{cm}$ and their mean diameter was $0.41(0.1) \mathrm{cm}$. The mean number of attempts was $1.48(0.93)$ and the mean number of attempts until successful UGVC was 1.31 (0.72). In more than $50 \%$ of cases, only one attempt was needed to achieve UGVC. The mean time needed for the procedure was 74.70 (73.72) seconds; the mean time to successful cannulation was 58.72 (56.87) seconds. Complete view of the needle (CVN) was accomplished in $41.7 \%$ of procedures, while partial view of the needle (PVN) occurred in $42 \%$ of procedures (Figs. 4, 5, 6). Repositioning the needle/guidewire (RNG) was necessary for successful UGVC in $49 \%$ of procedures (Fig. 7). Complications included: (a) $26.3 \%$ vessel perforation/wrong guidewire positioning (VP/WGP) and (b) $4.3 \%$ successful

Table 1 Descriptive presentation of the main variables of the ultrasound-guided vascular cannulation for inexperienced operators $(\mathrm{cm}$ : centimeters; s: seconds; SD: standard deviation)

\begin{tabular}{lclccl}
\hline $\mathrm{n}=300$ & Minimum & Maximum & Median & Mean & SD \\
\hline Depth $(\mathrm{cm})$ & 0.50 & 1.90 & 0.85 & 0.90 & 0.34 \\
Diameter $(\mathrm{cm})$ & 0.20 & 0.65 & 0.40 & 0.41 & 0.10 \\
Number of attempts & 1.00 & 7 & 1.00 & 1.48 & 0.93 \\
$\begin{array}{l}\text { Time for procedure } \\
\quad 14.00\end{array}$ & 349.00 & 40.00 & 74.70 & 73.72 \\
$\quad$ & & & & & \\
\hline
\end{tabular}

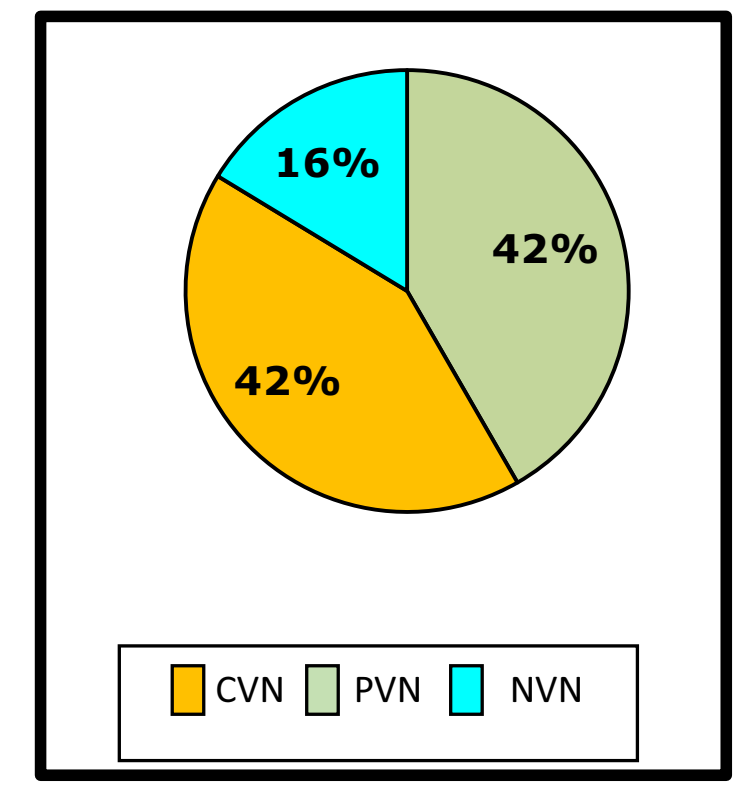

Fig. 4 View of the needle during UGVC (CVN: complete view of the needle; PVN: partial view of the needle; NVN: no view of the needle)

vessel puncture, followed by failure to accomplish subsequent cannulation. The global success rate in the training model was $79.7 \%$ (79.3\% in TA/OP and $80 \%$ in LA/IP); the rate of success on first attempt was $66.9 \%$. Table 2 presents the frequencies of the number of attempts necessary for successful UGVC.

\section{Discussion}

Ultrasound has been established as a therapeutical-diagnostic tool to be used on paediatric patients, as it is a noninvasive and highly profitable system for health screening. In addition, this system makes it possible to assess different organs and organic systems and to diagnose infrequent complications [22-26] Vascular cannulation has experienced a major advance with the use of ultrasound-based guidance. However, such an approach requires a learning process, which should ideally be carried out in simulation models. The learning curve was not evaluated in this study, because the main objective of this work was the theoretical-practical training of inexperienced/untrained operators on ultrasound-guided vascular cannulation. To achieve that, a training model was used [18]. Consideration was given to the model's similarities with paediatric patients, its versatility, repeatability and its low cost, as these were its most relevant differential characteristics with respect to other simulation models or simulators $[16,17,19,20]$. In an earlier study by our group [13, 14], more than $80 \%$ paediatric patients showed femoral and jugular vessel depths between 0.5 and 

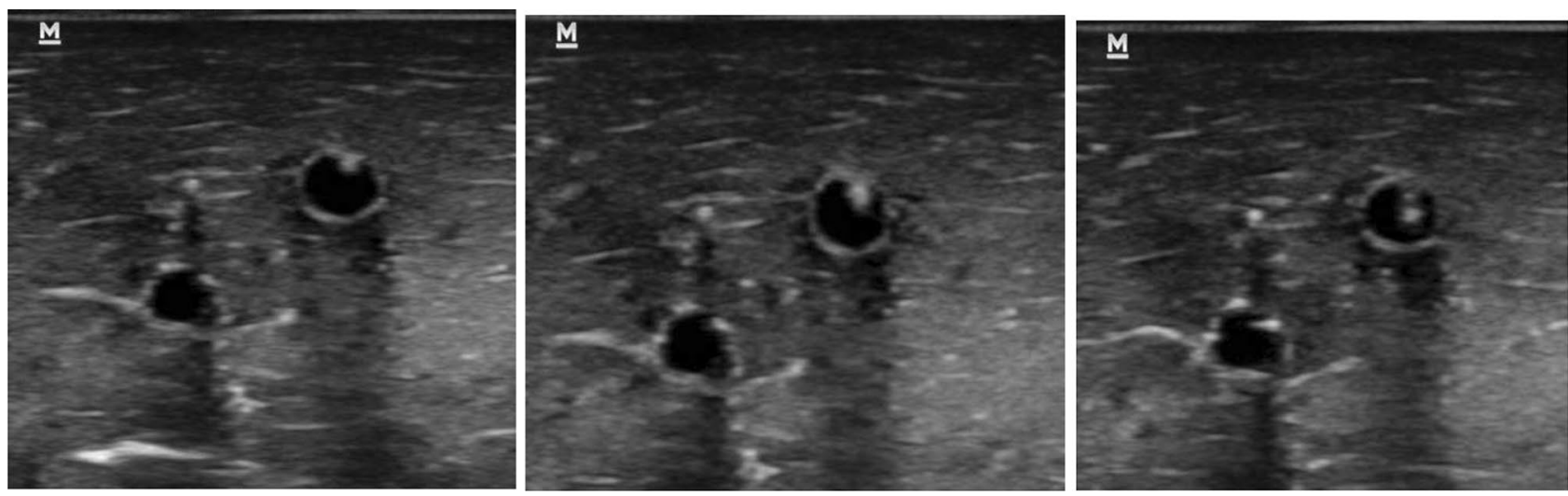

Fig. 5 Visualisation of the needle tip in the out-of-plane vascular cannulation. It can be observed the deformity of the vessel anterior wall in its contact with the puncture needle

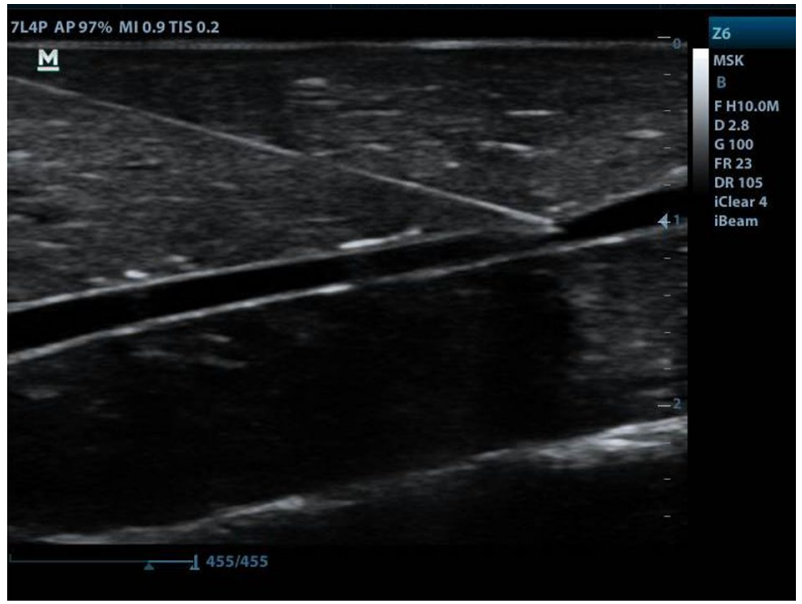

Fig. 6 Visualisation of the needle track in the in-plane vascular cannulation. It can be observed that the vessel anterior wall is deformed by its contact with the puncture needle

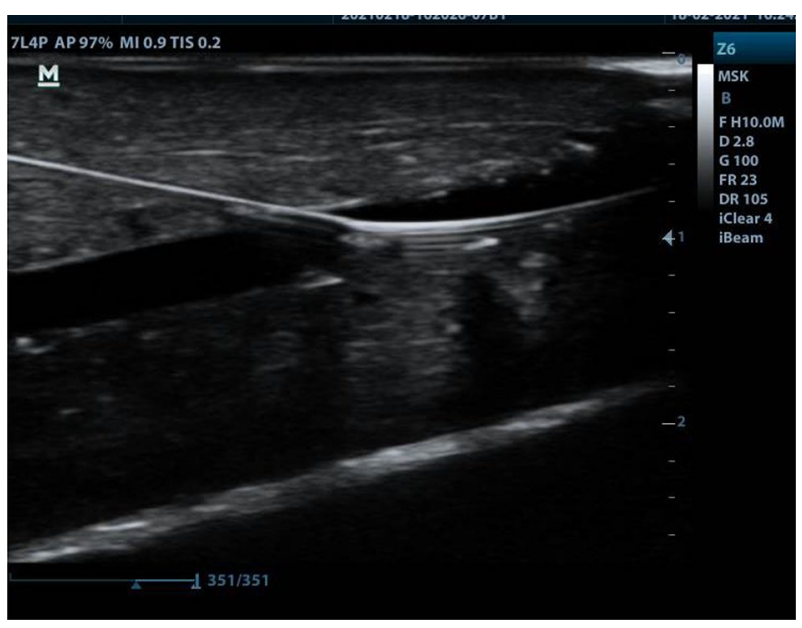

Fig. 7 Advance of the guide inside the vascular structure during the in-plane cannulation in the simulation model
Table 2 Percent distribution of the number of attempts needed for successful UGVC in the training model

\begin{tabular}{lc}
\hline $\begin{array}{l}\text { Number of } \\
\text { attempts }\end{array}$ & $\%$ Success \\
\hline 1 & 66.9 \\
2 & 22.2 \\
3 & 7.5 \\
4 & 2.1 \\
5 & 0.8 \\
7 & 0.4 \\
\hline
\end{tabular}

$1 \mathrm{~cm}$, and more than $50 \%$ of patients showed femoral vessel diameters between 0.20 and $0.30 \mathrm{~cm}$ and jugular vessel diameters between 0.50 and $0.65 \mathrm{~cm}$ (Figs. 3, 4). On this basis, we designed a training model to emulate the different scenarios that could potentially occur in paediatric UGVC. The mean depth of vessels to be cannulated was $0.90 \mathrm{~cm}$ and the mean diameter was $0.41 \mathrm{~cm}$. These data support the reliability of the model for use in paediatric patients. A good view of the needle is essential in UGVC to perform the technique safely and prevent complications. This is, however, a controversial and subjective matter, associated to large inter-observer variability [33-38]. We addressed this issue by subdividing this variable into three subcategories: complete view of the needle $(\mathrm{CVN})$; partial view of the needle (PVN); and no view of the needle (NVN) during the procedure. These subcategories were determined by an independent observer with previous experience in this technique, so as to reduce subjectivity. In this study, CVN was accomplished in less than $50 \%$ of procedures, while NVN occurred in $16 \%$ of them. The needle tip can subjectively be considered to have been visualized in the ultrasound machine or scanner while it is not so in practice, due to it being a part of this, or an artifact developed during the insertion of the needle. This fact can be related to complications, such as vessel posterior wall perforation or cannulation of a wrong 
vessel. In a series published by Moak et al. [34], the CVN rate was $66 \%$ according to the operators, but only $6 \%$ according to reviewers experienced in analysing video records of this technique. In a review of relevant literature [35-39], repositioning manoeuvres were necessary for successful UGVC. In our study, repositioning the needle or guidewire (RNG) was necessary in half the procedures and was more frequent with smaller vessel diameters, TA/OP punctures and punctures perpendicular to vessel (since the tip of the needle might reach the posterior vessel wall thus impairing insertion of the guidewire). The global success rate with our training model was $79.7 \%$. In a training program for resident physicians, in which a commercially available UGVC model designed by Thomas et al. [40] was used, a similar success rate was accomplished (80.8\%). However, Erickson et al. [35] reached a total success rate of $100 \%$. Such differences could be due to the degree of difficulty associated to every simulation model; for example, the mean diameter of the punctured vessels was $0.41 \mathrm{~cm}$ in our series, but $0.56 \mathrm{~cm}$ in theirs. In a peripheral vein UGVC study with a population of 169 adult patients, Panebianco et al. [36] reported a $90 \%$ success rate in 3 attempts. This rate fell below $56 \%$ in vessels with less than a $0.3 \mathrm{~cm}$ diameter, and rose to $92 \%$ in vessels with more than a $0.6 \mathrm{~cm}$ diameter. The authors concluded that the probability of success increased 1.79 per millimetre in vessel diameter, but dropped in vessels located more than $1.6 \mathrm{~cm}$ deep. This finding was also reported by Grebenik et al. [41] in a comparison between adult and paediatric patients, as well as in comparisons between paediatric patients of different age and weight ranges. They reported the lowest success rates in patients with less than $10 \mathrm{~kg}$ body weight or those younger than 1 year. The mean time needed to cannulation in our model was $58.7 \mathrm{~s}$. We measured the time from skin penetration until verification of a correct position of the needle within the vessel. In a series by Erickson et al. [35], a mean of $11 \mathrm{~s}$ for vessel penetration was reported, although they measured the time from skin penetration until the emergence of the fluid within the vessel. Other series described similar results. For example, Phelan et al. [38] reported $17.56 \mathrm{~s}$ until extraction of the fluid within the vascular structure of the model for UGVC with an echorefractory needle, as compared with $19.22 \mathrm{~s}$ for UGVC with a standard puncture needle. Notice that the diameter of cannulated vessels in the mentioned study was $0.8 \mathrm{~cm}$, which corresponded to an average adult patient. Furthermore, since the time required for inserting the guidewire or catheter into the vessel was not included, the time to vascular cannulation was underestimated. Moreover, it can be speculated that the success rate might be overestimated based on the fact that in up to $4 \%$ of our correct punctures, subsequent cannulation was not possible. The rate of success on first attempt was $67 \%$ in our study. In general, the mean number of attempts needed to achieve cannulation is inversely correlated with success in performing the technique. In this study, 1.48 attempts were required on average. Tomas el al. [40] reported similar results with a training model, where the number of attempts fell from 1.5 to 1 after participants received a period of training plus explanation of the essentials of the technique. In other studies carried out with adult patients, e.g. Barsuk et al. [42], a reduction in the number of attempts was described, from 1.74 with the traditional 'blind' cannulation to 1.32 with the UGVC technique. Ueda et al. [43] found a significant association between the rate of success on first attempt and the magnitude of vessel diameter. A further advantage of the UGVC approach, described in the literature, is a reduction in the complications rate [29, 37, 44, 45].

Stone et al. [24] emphasized the importance of monitoring the needle tip to reduce the rate of vascular complications, because failure to see it may lead to unadvertised puncture of vital anatomical structures or posterior vessel walls, or to unsuccessful cannulation [37, 45]. In a published series of adult patients, Vogel et al. [37] reported around $20 \%$ prevalence of accidental puncture of the posterior wall of the internal jugular vein; a finding also reported by Song et al. [44] in a paediatric study involving the radial and posterior tibial arteries. In other studies, e.g. that of Blaivas et al. [45], who used a mannequin torso, $64 \%$ operators accidentally punctured the posterior wall of the jugular vein during cannulation. With our model, we found both wrong guidewire positioning and $26.3 \%$ vessel perforation (the latter could be underestimated, since cannulation is sometimes successfully achieved in spite of unadvertised perforation of the posterior wall). In a study by Moon et al. [46], where a 34\% incidence of posterior wall perforation was reported, such complication was verified by dissembling the model, refilling the vascular structure with fluid and observing whether the fluid emerged from one side or both sides of the structure. Fluid emerging from two orifices indicated perforation of the posterior wall was confirmed. In our study, we did not carry out such verification; thus the rate of posterior wall perforation might potentially be higher than described. Finally, we would like to highlight that even with a UGVC training model used by inexperienced operators who carried out a restricted number of punctures, a global view of the technique, as well as the success and complication rates, could be obtained, which contributed to lessening the UGVC learning curve.

\section{Declarations}

Conflict of interest The authors declare that: (a) they have no financial or personal relationship, present or past, which could bias or inadequately influence the making of this work; (b) they have not and 
will not receive any financial compensation for the study design, data collection or analysis, manuscript preparation or submission for publication.

Ethical statements This study was designed according to the basic principles of the Declaration of Helsinki of the World Medical Association [21]. The highest levels of professionalism and confidentiality were applied and the national regulations for data protection were observed. Participants' right to confidentiality was granted and their identities were coded. Only authorized staff had access to identification-related personal information for data verification purposes. This research project was approved by the Ethics Committee for Clinical Research of the Mother and Child University Hospital of the Canary Islands (Complejo Hospitalario Universitario Insular-Materno Infantil de Canarias; Id: CEIm-CHUIMI-2016/883). Trainees participated voluntarily and anonymously, and they agreed to results publication.

Informed consent All participants (operators and patients collected data) were asked to sign informed consent.

\section{References}

1. Armenteros-Yeguas V, Gárate-Echenique L, Tomás-López MA, Cristóbal-Domínguez E, Moreno-de Gusmão B, Miranda-Serrano $B$ et al (2017) Prevalence of difficult venous access and associated risk factors in highly complex hospitalised patients. J ClinNurs. 26(23-24):4267-4275. https://doi.org/10.1111/jocn.13750

2. Loon FHJV, Puijn LAPM, Houterman S, Bouwman ARA (2016) Development of the A-DIVA Scale: a clinical predictive scale to identify difficult intravenous access in adult patients based on clinical observations. Medicine (Baltimore) 95(16):e3428. https:// doi.org/10.1097/MD.0000000000003428

3. Piredda M, Fiorini J, Facchinetti G, Biagioli V, Marchetti A, Conti $F$ et al (2019) Risk factors for a difficult intravenous access: a multicentre study comparing nurses' beliefs to evidence. J ClinNurs. 28(19-20):3492-3504. https://doi.org/10.1111/jocn.14941

4. Rodriguez-Calero MA, Fernandez-Fernandez I, Molero-Ballester LJ, Matamalas-Massanet C, Moreno-Mejias L, de Pedro-Gomez JE et al (2018) Risk factors for difficult peripheral venous cannulation in hospitalised patients. Protocol for a multicentre case-control study in 48 units of eight public hospitals in Spain. BMJ Open 8(2):e020420. https://doi.org/10.1136/bmjopen2017-020420

5. Ehrhardt BS, Givens KEA, Lee RC (2018) Making it stick: developing and testing the difficult intravenous access (DIVA) tool. Am J Nurs 118(7):56-62. https://doi.org/10.1097/01.naj.0000541440. 91369.00

6. Acuña J, Sorenson J, Gades A, Wyatt R, Stea N, Drachman M et al (2020) Ultrasound: overcoming the challenge of difficult peripheral intravenous access in the emergency department. J Ultrasound Med. 39(10):1985-1991. https://doi.org/10.1002/jum.15303

7. Saugel B, Scheeren TWL, Teboul JL (2017) Ultrasound-guided central venous catheter placement: a structured review and recommendations for clinical practice. Crit Care 21(1):225. https://doi. org/10.1186/s13054-017-1814-y

8. van Loon FHJ, Buise MP, Claassen JJF, Dierick-van Daele ATM, Bouwman ARA (2018) Comparison of ultrasound guidance with palpation and direct visualisation for peripheral vein cannulation in adult patients: a systematic review and meta-analysis. Br J Anaesth. 121(2):358-366. https://doi.org/10.1016/j.bja.2018.04. 047

9. Presley B, Isenberg JD (2020) Ultrasound Guided Intravenous Access. In: StatPearls [Internet]. Treasure Island (FL): StatPearls Publishing. https://www.ncbi.nlm.nih.gov/books/NBK525988/.
https://www.ncbi.nlm.nih.gov/books/NBK525988/. Accessed 31 Jul 2020

10 Franco-Sadud R, Schnobrich D, Mathews BK, Candotti C, AbdelGhani S, Perez MG et al (2019) Recommendations on the use of ultrasound guidance for central and peripheral vascular access in adults: a position statement of the society of hospital medicine. $\mathrm{J}$ Hosp Med. 14:E1-E22. https://doi.org/10.12788/jhm.3287

11. Gottlieb M, Sundaram T, Holladay D, Nakitende D (2017) Ultrasound-guided peripheral intravenous line placement: a narrative review of evidence-based best practices. Western J Emerg Med 18(6):1047-1054

12. Schmidt GA, Blaivas M, Conrad SA, Corradi F, Koenig S, Lamperti $\mathrm{M}$ et al (2019) Ultrasoundguided vascular access in critical illness. Intensive Care Med 45(4):434-446. https://doi. org/10.1007/s00134-019-05564-7

13. LópezÁlvarez JM, Pérez Quevedo O, Ramírez Lorenzo T et al (2018) Ultrasound-guided vascular cannulation. Experience in critically ill pediatric patients. Arch Argent Pediatr 116(3):204-209

14 LópezÁlvarez JM, Pérez Quevedo O, Santana Cabrera L et al (2017) Vascular ultrasound in pediatrics: estimation of depth and diameter of jugular and femoral vessels. J Ultrasound 20:285-292. https://doi.org/10.1007/s40477-017-0272-3

15. Troianos CA, Hartman GS, Glas KE, Skubas NJ, Eberhardt RT, Walker JD et al (2012) Special articles: guidelines for performing ultrasound guided vascular cannulation: recommendations of the American Society of Echocardiography and the Society Of Cardiovascular Anesthesiologists. AnesthAnalg 114(1):46-72

16. Nolting L, Hunt P, Cook T, Douglas B (2016) An inexpensive and easy ultrasound phantom: a novel use for SPAM. J Ultrasound Med 35(4):819-822. https://doi.org/10.7863/ultra.14.06023

17. Hauglum SD, Crenshaw NA, Gattamorta KA, Mitzova-Vladinov G (2018) Evaluation of a low-cost, high-fidelity animal model to train graduate advanced practice nursing students in the performance of ultrasound-guided central line catheter insertion. SimulHealthc 13(5):341-347. https://doi.org/10.1097/SIH.0000000000 000337

18. Pérez-Quevedo O, López-Álvarez JM, Limiñana-Cañal JM, LoroFerrer JF (2016) Design and application of model for training ultrasound-guided vascular cannulation in pediatric patients. Med Intensiva 40(6):364-370

19 Hocking G, Hebard S, Mitchell CH (2011) A review of the benefits and pitfalls of phantoms in ultrasound-guided regional anesthesia. RegAnesth Pain Med. 36(2):162-170. https://doi.org/10. 1097/aap.0b013e31820d4207

20. Wagner M, Hauser K, Cardona F, Schmölzer GM, Berger A, Olischar $\mathrm{M}$ et al (2018) Implementation and evaluation of training for ultrasound-guided vascular access to small vessels using a low-cost cadaver model. PediatrCrit Care Med. 19(11):e611-e617. https://doi.org/10.1097/PCC.0000000000001721

21. World Medical Association (2013) World Medical Association Declaration of Helsinki: ethical principles for medical research involving human subjects. JAMA 310(20):2191-2194

22. Vitale V, Rossi E, Di Serafino M, Minelli R, Acampora C, Iacobellis F, D'Errico C, Esposito A, Esposito F, Vallone G, Zeccolini M (2020) Pediatric encephalic ultrasonography: the essentials. J Ultrasound. 23(2):127-137. https://doi.org/10.1007/ s40477-018-0349-7

23. Tufano A, Minelli R, Rossi E, Brillantino C, Di Serafino M, Zeccolini M, Cantisani V, Vallone G (2020) Inferior epigastric artery pseudoaneurysm secondary to port placement during a robotassisted laparoscopic radical cystectomy. J Ultrasound. https://doi. org/10.1007/s40477-020-00442-1

24. Brillantino C, Rossi E, Baldari D et al (2020) Duodenal hematoma in pediatric age: a rare case report. J Ultrasound. https://doi.org/ $10.1007 / \mathrm{s} 40477-020-00545-9$ 
25. Buonsenso D, Chiaretti A, Curatola A, Morello R, Giacalone M, Parri N (2021) Pediatrician performed point-of-care ultrasound for the detection of ingested foreign bodies: case series and review of the literature. J Ultrasound 24(1):107-114. https://doi.org/10. 1007/s40477-020-00452-z

26 Bauer AS, Meinen R, Devous K, Al-Subu A, Cowan E (2020) Introduction of point of care ultrasound into the neonatal intensive care unit. J Ultrasound. 23(4):631-632. https://doi.org/10.1007/ s40477-019-00419-9

27. Hebard S, Hocking G (2011) Echogenic technology can improve needle visibility during ultrasound-guided regional anesthesia. RegAnesth Pain Med 36(2):185-189

28. Karstrup S, Brøns J, Morsel L, Juul N, von der Recke P (2002) Optimal set-up for ultrasound guided punctures using new scanner applications: an in-vitro study. Eur J Ultrasound 15(1-2):77-84

29. Stone MB, Moon C, Sutijono D, Blaivas M (2010) Needle tip visualization during ultrasoundguided vascular access: short-axis vs long-axis approach. Am J Emerg Med Marzo de 28(3):343-347

30 Giurazza F, Contegiacomo A, Corvino F, Basile A, Niola R (2021) Scrubbing needles: a simple and costless technique to improve needle tip visibility during US-guided liver interventions. J Ultrasound. https://doi.org/10.1007/s40477-021-00561-3

31. Reusz G, Sarkany P, Gal J, Csomos A (2014) Needle-related ultrasound artifacts and their importance in anaesthetic practice. $\mathrm{Br} \mathbf{J}$ Anaesth 112(5):794-802

32. Chen HE, Yovanoff MA, Pepley DF, Prabhu RS, Sonntag CC, Han DC et al (2019) Evaluating surgical resident needle insertion skill gains in central venous catheterization training. J Surg Res. 233:351-359. https://doi.org/10.1016/j.jss.2018.07.040

33. Giurazza F, Corvino F, Contegiacomo A, Marra P, Lucarelli NM, Calandri M, Silvestre M, Corvino A, Lucatelli P, De Cobelli F, Niola R, Cariati M, Italian College of Interventional Radiology (ICIR) Rising Stars Group (2019) Safety and effectiveness of ultrasound-guided percutaneous transhepatic biliary drainage: a multicenter experience. J Ultrasound. 22(4):437-445. https://doi. org/10.1007/s40477-019-00399-w

34. Moak JH, Lyons MS, Wright SW, Lindsell CJ (2011) Needle and guidewire visualization in ultrasound-guided internal jugular vein cannulation. Am J Emerg Med 29(4):432-436

35. Erickson CS, Liao MM, Haukoos JS, Douglass E, DiGeronimo M, Christensen E et al (2014) Ultrasound-guided small vessel cannulation: long-axis approach is equivalent to short-axis in novice sonographers experienced with landmark-based cannulation. West J Emerg Med 15(7):824-830

36. Panebianco NL, Fredette JM, Szyld D, Sagalyn EB, Pines JM, Dean AJ (2009) What you see (sonographically) is what you get: vein and patient characteristics associated with successful ultrasound-guided peripheral intravenous placement in patients with difficult access. AcadEmerg Med 16(12):1298-1303
37. Vogel JA, Haukoos JS, Erickson CL, Liao MM, Theoret J, Sanz GE et al (2015) Is long-axis view superior to short-axis view in ultrasound-guided central venous catheterization? Crit Care Med 43(4):832-839

38. Phelan MP, Emerman C, Peacock WF, Karafa M, Colburn N, Buchanan K (2009) Do echo-enhanced needles improve time to cannulate in a model of short-axis ultrasound-guided vascular access for a group of mostly inexperienced ultrasound users? Int J Emerg Med 2(3):167-170

39. Blaivas M, Brannam L, Fernandez E (2003) Short-axis versus long-axis approaches for teaching ultrasound-guided vascular access on a new inanimate model. AcadEmerg Med 10(12):1307-1311

40. Thomas SM, Burch W, Kuehnle SE, Flood RG, Scalzo AJ, Gerard JM (2013) Simulation training for pediatric residents on central venous catheter placement: a pilot study. PediatrCrit Care Med J SocCrit Care Med World Fed Pediatr Intensive Crit Care Soc 14(9):e416-423

41. Grebenik CR, Boyce A, Sinclair ME, Evans RD, Mason DG, Martin B (2004) NICE guidelines for central venous catheterization in children. Is the evidence base sufficient? Br J Anaesth. 92(6):827-830

42. Barsuk JH, McGaghie WC, Cohen ER, O’Leary KJ, Wayne DB (2009) Simulation-based mastery learning reduces complications during central venous catheter insertion in a medical intensive care unit. Crit Care Med 37(10):2697-2701

43. Ueda K, Puangsuvan S, Hove MA, Bayman EO (2013) Ultrasound visual image-guided vs Doppler auditory-assisted radial artery cannulation in infants and small children by non-expert anaesthesiologists: a randomized prospective study. $\mathrm{Br} \mathrm{J}$ Anaesth 110(2):281-286

44. Song I-K, Choi J-Y, Lee J-H, Kim E-H, Kim H-J, Kim H-S et al (2016) Short-axis/out-of-plane or longaxis/in-plane ultrasoundguided arterial cannulation in children: a randomised controlled trial. Eur J Anaesthesiol 33(7):522-527

45. Blaivas M, Adhikari S (2009) An unseen danger: frequency of posterior vessel wall penetration by needles during attempts to place internal jugular vein central catheters using ultrasound guidance. Crit Care Med 37(8):2345-2349

46. Moon CH, Blehar D, Shear MA, Uyehara P, Gaspari RJ, Arnold $\mathrm{J}$ et al (2010) Incidence of posterior vessel wall puncture during ultrasound-guided vessel cannulation in a simulated model. AcadEmerg Med 17(10):1138-1141

Publisher's Note Springer Nature remains neutral with regard to jurisdictional claims in published maps and institutional affiliations. 